\title{
Product Placement and Brand Equity
}

\author{
Margherita Corniani ${ }^{*}$
}

\begin{abstract}
Product placement is the planned insertion of a brand within a movie, a fiction, etc. It can be used with other communication tools (i.e. advertising, sales promotions, etc.) in order to disseminate brand awareness and characterize brand image, developing brand equity.

In global markets, product placement is particularly useful for improving brand equity of brands with a well established brand awareness.
\end{abstract}

Keywords: Product Placement; Brand Equity; Movies; Brand Image; Brand Awareness; Global Competition

\section{Product Placement}

Product placement (or product tie-in) is a corporate communication tool which allows us to plan and carry out the placement of a product or brand within the scenes of a film within a specific budget and defined contractual terms ${ }^{1}$.

Typically linked to the world of cinema ${ }^{2}$, planned product placement is also used in television shows, fiction, telefilms, cartoon ${ }^{3}$ series, software (where it takes the name advertainment ${ }^{4}$ ) as well as in a variety of artistic fields other than cinema ${ }^{5}$ (sculpture, photography and comic strips, to name but a few).

In particular, in the world of cinema production, where product placement has become widespread $^{6}$, the technique used consists in identifying a scene or scenes in the actual film script which are most suitable for the placement (subsequently contractually defined and regulated between the parties) of the promoting company's product or brand. Sometimes, the opposite can happen and a scene may be adapted or specifically created to include a certain product or brand. Hence there are three distinct types of placement:

- the brand is shown on a sign or the product is present in a scene;

- the product is used for its real purpose (a pair of sunglasses worn to protect against the sun) or for other purposes (the sunglasses are used as a tool to transfer a message ${ }^{7}$;

\footnotetext{
*Assistant Professor of Management, University of Milan-Bicocca (margherita.corniani@ unimib.it)
} 
- the product or brand is mentioned by the actors.

These different types of placement are developed in such a way so as to have either greater or lesser visibility according to the agreements reached between parties $^{8}$. Thus the product may appear centre-stage or in the background of a scene; it may be used once or several times over ${ }^{9}$; or it may simply be mentioned, or even praised, including perhaps some comparison to the main competitor product.

The agreements between the parties may be drawn up in a very detailed manner (indicating the specific scene, and form of product or brand appearance in very precise terms), or in much more general terms ${ }^{10}$ with the simple identification of broad criteria for product placement.

\section{Product Placement in Corporate Communication}

As with other corporate communication tools, where costs and benefits are management controllable, product placement has its own very distinctive features, which determine the advantages and limits of its use $\mathrm{e}^{11}$.

As far as advantages are concerned, product placement offers:

- a pre-arranged 'emphasis effect';

- planned appearance of products and brands;

- development of active audience interest;

- a predetermined level of product and brand crowding;

- high audience segmentation;

- the opportunity to present product categories for which advertising constraints and limits may be in place;

- gradual investment.

On the other hand, as far as limits are concerned, product placement involves the following:

- timescales and methods of use linked to the connotations of a cinema product;

- complete programming of the scenes in which the product will be placed but not of the effects - whether positive or negative - which might derive as a result.

\subsection{Advantages of Product Placement}

'Emphasis effect' - The introduction of products and brands in films is carried out with the intention of reproducing real life settings in which the products and brands appear in everyday situations of normal use. In this way, product placement allows us to attribute the implication of reality to the film, without interrupting the natural flow of the scene itself, but rather improving and enriching it with further elements. Therefore, product placement can integrate perfectly into a film and be quite naturally accepted by the public. This holds true even when specific emphasis on the product or brand itself is planned, as sometimes happens, for example, in the event of a particularly ostentatious appearance or unconventional use of the product in question. The emphasis effect therefore rests on the audience's natural acceptance of the product's or brand's presence in the film. This is developed 
through suitable artifices which make it possible to concentrate spectator attention on the product, without distracting interest from the scene or the film's action.

Planned appearance of products and brands - The placement of brands and products within films allows a natural setting to be developed for the products, which are then portrayed in either conventional or unconventional everyday situations of use. Furthermore, cinema film allows the use of colour, movement and sound, meaning products and brands can be shown at their very best, and often with timeframes and a quality of exposure that cannot be equalled by any other communication tool.

Active audience interest - One feature of product placement is its effect on the active interest of the audience ${ }^{12}$ and the opportunity to exploit the emotional involvement of the public exposed to its message. The attention with which people follow the development of the scenes of a film and the emotional involvement which makes them participate in the action and the scenes being played out cannot be matched by any other form of corporate communication media.

Pre-determined level of crowding - A further feature of product placement is the predeterminability of product and brand crowding in a film, in other words, in the corporate communication support medium. Dense crowding typically results in lower visibility for the corporate communication itself, which thereby translates into lower efficacy of the communication media employed.

In product placement, crowding tends to be contained and its first limit is set by the actual film itself. The success of a film, and the profits to be made from it, are secondary to public and critical appreciation; film production companies must therefore limit product placement in films. Crowding is naturally constrained by the public's ability to accept the presence of brands in scenes. Placement should not be perceived as a disruption but rather accepted as something that furthers the development of the film's action. Obviously this threshold is extremely variable and depends to a great extent on the target public profile.

High audience segmentation - Product placement also permits typological segmentation of the public it reaches. Every film has its own particular identity and this is usually quite evident even in the advertising trailers, which aim to attract specific sectors of the public. So product placement has a highly segmentational tool available to it; one that can be used to direct corporate communication at a specific public that is well defined within its own distinctive profile.

Presentation of product categories for which advertising constraints and limits may be in place - Product placement also offers the opportunity to show product categories normally banned from advertising communication ${ }^{13}$. The make-believe world of cinema is, in this case, allowed a much broader margin of freedom compared to what may be permitted in traditional corporate communication such as advertising ${ }^{14}$.

Gradual investment - Finally, product placement involves a gradual investment process, which makes its use highly flexible. In particular, product placement is more flexible than advertising, which - as it works on the basis of message frequency and repetition rate - requires minimum investment thresholds that are, in any case, quite high and dependent on the competitiveness of each specific sector $^{15}$. 


\subsection{Limits of Product Placement}

Timescales and methods of use deriving from a cinematographic product - The gradual nature of investment, most certainly an advantageous aspect of the use of this medium, contrasts however with the impossibility of message repetition, which is a distinct limitation of product placement as a corporate communication tool.

Message frequency and repetition, indispensable factors in advertising to counteract passive audience attention and delay the natural drop in product recall, are on the contrary precluded features in product placement, which usually allows the target segment to be reached only once.

Product placement is of course linked to timing (time of appearance and possible repeats) and to the method of use of the cinematographic product (cinemas with relevant technological equipment, videocassettes, etc.). As a result, corporate communication, linked to the presence of a product or brand in a film, must be developed with a view to the forms of distribution planned for the film in question $^{16}$.

As far as timeframes and methods of use of cinema products are concerned, we must bear in mind that the success and distribution of a film cannot typically be foreseen beforehand. Indeed, hand in hand with widely distributed films that become both nationally and internationally well known, there are others of very modest success. Even famous directors and actors, who are often backed by quite substantial advertising investments, can create unappreciated unacknowledged films, whose effective lifespan is limited to just a few screenings for a few evenings at a limited number of venues.

As product placement is associated to a film, it is directly affected by the film's success or lack of success. In the first case, it might therefore be distributed nationally and internationally as well as on television and home video. This might sometimes even involve the opportunity for repeat viewing by the same audience. In the second case, i.e. when - on the other hand - the film is not a success, any product placement within it is also exposed to viewing by just a small number of pioneers and it will be very difficult for it to reach any other channels of distribution.

Complete programming of scenes - Product placement allows very detailed programming of the scenes in which the product/brand appears, thus guaranteeing the promoting company an accurate identity tool to use to present its corporate product range. However, the effects of placement on brand awareness cannot be planned in any way. This depends on the appreciation of the public and the public is influenced by a large number of factors, most of which cannot be controlled by the promoting company (e.g. the film's appeal, perceptions associated with how the corporate product range or brand is placed, the promotional slogan supporting the film's distribution, critical opinion, etc.).

On the whole, it may be said that product placement is used as a corporate communication tool linked to the values, methods and timeframes of the work, typically a film, within which it is placed. As such, placement amplifies the effects of the film on the awareness and perception of the brand/product, but - at the same time - limits the opportunities available to the company to intervene or control. Therefore, whilst, on the one hand, this action on active audience interest is constrained by the variability of the values and success of the medium involved (the film); on the other hand, there lies the opportunity to work with high impact 
media, such as cinema and television. However, in the latter case, timeframes and methods of distribution cannot be programmed and this factor limits any means of forecasting the spatial and temporal distribution of the corporate communication.

\section{Product Placement Management}

Product placement usually involves a promoting company and a movie production company. The former aims to place a specific product or brand in a given context, while the latter searches for correct remuneration in return for granting visibility to the 'placement'.

Depending on the activities performed, the operational aspects of the placement can vary.

First of all, some initiatives are limited to the placement of the promoting company's product or brand in the film, but they may also extend to their management in collateral activities such as advertising posters or the promotional trailers ${ }^{17}$ that launch the film. These initiatives create products that are separate from the film because they are conceived specifically to market it. The trailers are destined to have more visibility than the film they promote, and they are communicated by numerous media and address a far broader target than the audiences who will actually watch the film.

In addition to the actual 'placements', the parties may agree to develop licensing activities or other types of promotional programmes.

Through licensing, cinema production houses grant other companies the right to exploit characters or images from a film, in exchange for the payment of royalties ${ }^{18}$. In numerous legal systems, this activity is regulated by a precise contract and allows the companies involved to develop and market products (and occasionally services too) that reproduce characters or settings from the film. This form of licensing is very widespread in the world of children's films (particularly cartoons), and it may take place with or without the placement being defined. In the first case in particular, licensing defines an additional element compared to product placement and helps to stabilise relations between film production and the company promoting the placement.

A product placement can also be associated with other forms of promotion, usually described as cross promotion or back-end promotion, through which promoting companies back the distribution of the film in which the product is placed, giving visibility to the film and to the association it establishes with the product (or brand) ${ }^{19}$. In these cases, the purpose of the communication is to inform the public of the existence of a precise product placement, for example, by proposing the main scenes from the film in which the placement occurs, or by referring to characters from the film in association with the product to be promoted.

The benefits of cross promotion are felt in particular by the promoting company which can thus make its association with the film known to the general public, drawing on its recognition and image on the market. On the other hand, film production companies also exploit the advantages of the communication created by the cross promotion, obtaining greater visibility for the film, which is promoted at the expense of the promoting company ${ }^{20}$.

Depending on the frequency with which this tool is employed, the companies involved may create organisational units whose purpose is specifically to manage it. 
In the case of cinema production, 'Executive Studios' are created to systematically manage placements within the films produced. It will therefore be the Executive Studios that analyse the screenplay, look for placement opportunities and contact any promoting companies that might be involved.

Promoting companies that invest regularly in placements can set up special units themselves, as Anheuser-Bush, Ford, AT\&T, Kodak and Coca-Cola (the 'heavy spenders' in this market ${ }^{21}$ ) have done in the United States, to analyse studios' proposals and to collaborate actively on the definition of the best positioning solutions.

'Product placement agencies' slot in between these players: they are professional structures that specialise in activating and managing this type of corporate communication tool.

These agencies first appeared in the second half of the 1980s, in the Hollywood $\operatorname{area}^{22}$, and they replace the specialised units of promoting companies and production houses, or work with them, dealing with the operational aspects of the placement process. Their activities start from an examination of the film in production, envisage the identification of potential placements of brands and products, and continue with the selection of promoting clients. They manage the placement on their behalf, draft the contract and protect the customers' interests when the scenes in which the product or brand will be placed are recorded.

The agencies can be contacted directly by promoting companies looking for a placement ${ }^{23}$ or by production companies wishing to identify possible promoters, when the producers are not in a position to manage the relations that would result from $\mathrm{it}^{24}$.

The product placement market is founded on the existence of finite and stable relations between parties that know each other and can establish trusting relationships. In many cases, it is the bonds of friendship and acquaintanceship, rather than specific contract clauses, that enable a contract to be developed and respected.

\subsection{Product Placement: Contracts and Methods of Remuneration}

In its most evolved forms, the agreement behind a product placement is defined in a contract drawn up between two parties, which establishes the fee that the promoting company undertakes to pay to the film production company and to any other involved parties. The fee may translate into a monetary contribution to the production or the supply of goods and materials useful for the scenes or to support the cast and the operators ${ }^{25}$.

This remuneration represents the main product placement cost for the promoting company and a revenue (or lower cost) for the film production company. It is usually defined on the basis of the marketing plan for the launch of the film in cinemas, and its subsequent distribution through other channels (purchase of rights by television networks, home videos, etc.). Compared to other, similar experiences, this plan creates expectations regarding the success of the film, and therefore its prospects for distribution ${ }^{26}$.

One element common to many product placement contracts ${ }^{27}$ is the 'transparency clause' which obliges the parties to consent to the disclosure of the contents of the agreement to external parties (for example journalists, television networks, government agencies, and so on $)^{28}$. 
Product placement contracts can be terminated if certain events envisaged during the development of the agreement occur or do not occur. The most frequent cause of the termination of a contact is the director's decision to eliminate the scene that was to contain the placement ${ }^{29}$. In other cases there may be disputes regarding a failure to respect particular contract clauses, which can result in lengthy and costly legal proceedings ${ }^{30}$.

Well-known professional figures are employed to limit the possibilities of contract default, and the cinema production companies and sponsor companies are generally involved. The higher the envisaged contribution to the production of a film by a promoting company, the lower the probability for the company that the director will cut the scenes in which its products or brands will be placed. As a result, because it can trigger larger economic commitments than placement alone ${ }^{31}$, cross promotion provides a guarantee for sponsor companies that the agreed product placement will actually be implemented at the production stage.

The remuneration of a placement, established when the contract is drafted, may be defined on the basis of one of the following alternatives, or a combination of them:

a) reduced costs for the film production house;

b) cross promotion;

c) a fee.

a) In the first case, the promoting companies make specific goods or services available to the production companies so that they may be employed in the production and/or used by the film crew.

b) In cross promotion, on the other hand, the cost of the placement is negotiated in the form of participation in the promotion of the film, for example the communication to promote the film (and the related product placement) at the promoting company's points of sale. In this sense, some product placement specialists maintain that promotions are the real remuneration for this communication tool, because they can be transformed rapidly into increased sales for the sponsor companies and the film studios ${ }^{32}$.

c) Payment of a fee envisages monetary remuneration by the promoting company to the film production company, but it is actually applied less frequently. For example, it is unusual to negotiate a fee when the products necessary to produce the film are expensive, like cars. Some directors and producers feel that payment of a fee puts pressure on the choice of the scenes to be kept in the film, reducing the director's freedom of action. However, the fee is usually close to $\$ 5,000$ (rarely exceeding \$20,000) and seems to be the simplest form of remunerating product placements in situations that do not envisage cross promotions or cannot be remunerated by the availability of expensive products ${ }^{33}$.

\section{Product Placement and Brand Equity Management}

Product placement, which has a number of distinctive characteristics, slots into the vaster system of corporate communication tools (advertising, sponsorship, sales promotion, direct marketing, merchandising, licensing, propaganda and public relations). 
These tools are linked by the goal they share: to convey a message to selected target groups, in order to transmit and make known a specific brand identity, which can help to maintain and develop brand equity.

The tools indicated operate with specific supports, for example support for an event, a personality, a palimpsest, a paper, a film and so on. What is more, by creating precise information flows to reach given targets they acquire specific quantitative (number of contacts per unit of time) and qualitative aspects (distinctive features of the programme, the publication, etc.) related to the media employed $^{34}$. By integrating the communication into the goals and targets of the message, the message conveyed by the product placement acquires qualitative and quantitative values (such as tone, style and frequency) from both the product/brand represented, and from the film, the scene and the method of exposure ${ }^{35}$.

Like other communication tools, product placement also demands preventive evaluation of the effect achievable and, after its use, verification of the effects actually achieved. From an economic-corporate perspective, this effect is the benefit obtained from meeting specific communication costs and it is only by comparing costs and benefits, and targets and results that the effectiveness and efficiency of the instruments activated can be calculated.

The choice of a specific communication tool and the identification of a suitable level of investment are the result of what can be defined as a causal approach to spending on communication. Every investment makes it possible to reach a precise goal, according to a cause-effect logic that makes it necessary to identify the goal in advance and to verify afterwards that it has been reached, calculating the effect achieved.

The effect of the communication must then be assessed with reference to the main goal of increasing brand equity. There are two useful indicators that make it possible, according to now widespread concepts, to define this equity on the basis of the company's functioning hypothesis ${ }^{36}$ : brand awareness and image ${ }^{37}$.

Awareness is a quantitative indicator that can vary according to a specific segment of demand's familiarity with a particular brand.

On the other hand, image is a quality indicator, summing up the connotations that a given segment of demand attributes to the brand under examination.

The brand image can therefore be associated to the degree of differentiation of a product range, as it is perceived by demand in a market characterised by the presence of specific products.

A brand may therefore develop very specific connotations that tend to distinguish it clearly from its competitors, directing it towards a precise market position. In the opposite case, and usually with the goal of increasing visibility, brand communication may be targeted by reducing its distinctive connotations in order to enhance the acceptability of a less specific, more widespread corporate product.

From a conceptual perspective, awareness and image are therefore inseparable aspects of the same phenomenon, brand equity, which can be examined by joint recourse to both indicators.

In particular, awareness has image to thank for establishing the conditions that allow it to expand. In fact, only when it is launched on the market and recognised by some portion of demand does this brand acquire a classification or image, at least with this segment of connoisseurs. However, great awareness presupposes that a brand is widespread among very broad (and heterogeneous) target universes, 
which means that it contains the distinctive characteristics that would make it a very characteristic and therefore specialist supply for specific demand segments.

Table 1: Product Placement and Brand Awareness

\begin{tabular}{|l|l|l|}
\hline & \multicolumn{2}{|c|}{ BRAND AWARENESS } \\
\hline PRODUCT & \multicolumn{1}{|c|}{ Low } & \multicolumn{1}{c|}{ High } \\
\hline Existing & Reese's Pieces (Hershey Food) & Coke (Coca-Cola) \\
\hline New & Romeo (Oakley) & Z3 Roadster (BMW) \\
\hline
\end{tabular}

The close link between awareness and image explains why the two concepts cannot be separated but must be considered with a single logical approach.

\subsection{Product Placement and Brand Awareness}

As a communication tool, product placement impacts on brand equity because it influences the degree of awareness of the brand and can, at the same time, affect its distinctive values and therefore its image.

The first aspect, awareness, can be examined with reference to certain typical situations (brands with a high level of awareness and brands with a low level of awareness), combined with the degree of novelty for the market of the products offered (existing or new product) (Table 1).

The comparison of the two values outlines certain typical situations to which product placement can be applied in various ways.

First of all, product placement does not seem to offer interesting potential for new brands that are not yet familiar. This communication tool places or uses the product (making the brand visible) in a film in a way that must appear entirely incidental in the spectator's eyes. So it is not suitable for unknown brands, which, being new, would not be noticed at all.

Similar considerations are valid for the launch of new products from little known brands. In this case too, a film does not guarantee the necessary visibility to the brand or the new product to achieve significant recollection. There are however non-traditional product placement solutions that can get round the limitations of poor awareness by attributing greater importance to the new product, as in the case of Romeo, a new model of sunglasses from Oakley, a brand that is only familiar to certain segments of the public.

In 'Mission Impossible 2' (M-I: 2, John Woo, USA, 2000), these sunglasses were used in an unconventional or 'improper' way (to transmit a secret message) and associated with the well-known star Tom Cruise. The visibility of the association and of the product was guaranteed simultaneously by the particular use of the sunglasses and the emphasis on them in the trailer to launch the film, which was screened repeatedly by television stations and in cinemas.

Product placement can also be used to develop awareness of products already on the market, even when they are from lesser known brands. One example is Reese's Pieces from Hershey Food Corp.. Reese's Pieces is a snack that competes directly 
with the popular M\&M's, which was associated with E.T. ${ }^{38}$ in an attempt to reach a threshold of awareness on the American market that would allow it to compete with the market leader. To be translated into awareness, the visibility achieved by its association with this familiar character had to be sustained by other communication tools, but it allowed Hershey Food to limit its spending in the first stage of the communication designed to reach the minimum threshold of national visibility ${ }^{39}$.

Product placement can be an important communication tool to sustain awareness of well-known brands, for both existing and new products. However, in these two situations, the potential of this tool differs in terms of support/development of awareness.

For well-known brands, product placement impacts on acquired awareness and tends to amplify it by associating the brand with a particular scene or character, or an unconventional use of the product presented. Spectators are already familiar with the brand and even a fleeting appearance is visible, making it possible to maintain the levels of product awareness already won with other forms of communication.

$\square$ In 'Hollow Man' (Paul Verhoeven, USA, 2000), several cans of Coca-Cola appear in a secret Pentagon laboratory, and it is only thanks to a change in the position of one of the cans that a scientist is aware of the presence of Kevin Bacon, who is invisible.

$\square$ In the 'Back to the Future' trilogy (Back to the Future, Back to the Future 2, Back to the Future 3, Robert Zemeckis, USA, 1984, 1989, 1990) Michael J. Fox asks for a can of Pepsi Cola in the various periods he finds himself in as he travels through time.

On the other hand, in the case of very well-known brands that propose new products, the operating scheme indicated above varies. On one hand the new product is not familiar and if it is to be seen and to attract the audience's interest it must be given important space in the film, giving it a certain visibility. But on the other hand, a well-known brand on a new product already has the force to attract the audience's attention, guaranteeing the product a degree of visibility which an unknown or little-known product could not obtain with the same amount of exposure.

Even if it is supported by a very well-known brand, a new product must be made more visible than a product already on the market. Visibility can be achieved in various ways; for example through longer exposure times, more numerous appearances or particular uses in important scenes in the film, as in the case of the BMW Z3 Roadster that is James Bond's new car in Goldeneye ${ }^{40}$. The association of the BMW model with the actor Pierce Brosnan, who plays the well-known secret agent, draws the audience's attention to the new car (new for the market and for 007), allowing the director to linger on the details of the car, as so often happens in this series of films.

And finally, product placement can also be exploited to develop brand awareness in developing countries. Using this tool, brands can achieve good awareness even where TV is not common: for example of the visibility achieved by da Coca-Cola and Lambretta in Italy in the early 1950s. 


\subsection{Product Placement and Brand Image}

Films do not only create awareness of the products presented, they also influence their image. In this sense, a product placement in a film (or in other forms like television serials, cartoons, etc.) conveys the message, and transfers its own specific values to it, in the way the latter are perceived by the audience.

The values of a scene or character are known in advance (before deciding a product placement), while the effects that can be achieved among the audience are changeable and unpredictable in all their implications. As a result, product placement makes it possible to plan and define in detail the association between the scene/character/use and the product/brand during the development of the film, in order to establish the production responsibilities, direction and brand ownership in the contract.

However, product placement cannot programme the hoped-for effects of a scene and the associations it contains. These effects depend on the associations that the audience makes with the scene and the entire film, the appreciation on which the success of the film depends and, therefore, the possibility of expanding or damping the values associated with the brand. In product placement, the choice of the setting and the characters that the brand is associated with, and the possibility of verifying its correct positioning during filming, reduce the risk of ineffective or even harmful placements $^{41}$.

Because it is a condition that amplifies the effect of the placement, the visibility of a popular brand inside a film can be a vehicle of positive but also of negative associations. For this reason, brands tend to value the possible effects of product placements very carefully, avoiding associations that are too innovative and potentially uncertain ${ }^{42}$. Clauses drafted to prevent any negative associations that may be harmful to the image are also included in the contracts ${ }^{43}$.

However, it is not always possible to control extreme situations, as we can see from the number of legal proceedings initiated against film production companies by businesses, for the damage that erroneous placements or contract default can cause, with negative consequences for brand equity ${ }^{44}$.

Where the effects on the brand image are concerned, product placement seems to offer different potential depending whether it addresses the transfer of distinctive image connotations in the case of new products, the development of distinctive connotations of the image of an existing product, or changes to the perceived characteristics of a product that is already known and distributed in the market (Table 2).

Table 2: Product Placement and Distinctive Characteristics of Brand Image

\begin{tabular}{|c|c|c|}
\hline & DISTINCTIVE CHARACTERISTICS OF BRAND IMAGE \\
\hline PRODUCT & Development/Transfer & Change \\
\hline Existing & Naya Water & Red Stirpe Beer \\
\hline New & $750(\mathrm{BMW})$ & - \\
\hline
\end{tabular}

With reference to the transfer of distinctive image connotations from a brand to a new product, we refer you to our comments regarding awareness. If the product placement is to influence image connotations, the only novelty related to a well- 
known brand must regard the product, as in the case of the BMW 750 in 'Tomorrow never dies ${ }^{45}$. Having guaranteed the visibility of a BMW car, the film transfers to the car the qualities associated with Bond himself, values that are however consistent with the BMW brand's image.

Product placement can also be used to develop the image connotations of an existing product. In this case it is necessary to define the image characteristics of products which, although they have been on the market for some time, are almost totally interchangeable with competitive products because they are part of a traditionally poorly differentiated supply, as in the case of mineral waters.

- Naya Water considers product placement a communication tool that can associate its range of mineral waters with qualities linked to valour, strength and courage, as we see in the film 'Shattered Image' (Raul Ruiz, USA, 1998) in which Anne Parillaud, who plays the femme fatale (the killer), drinks Naya Water, and in 'X-Men' (Brian Singer, USA, 2000) where the water is drunk by the human beings who are good and 'macho" 46 .

Finally, even if less frequently, product placement may help to change the system of distinctive characteristics of a corporate product, by associating a particular brand with scenes or characters that can modify its classification.

$\square$ For example, in the film 'The Firm',47, Red Stirpe, a low profile Jamaican beer appears in the hands of Tom Cruise and Gene Hackman, which made it popular with the public. However, modifying the brand image in this way has repercussions for brand awareness. If the beer were not known for its modest profile, the public might not have noticed its presence in the film, nor would it have been affected by this association with the well-known actors.

If the distinctive traits of a product are to be changed effectively, other tools are necessary, in addition to product placement.

In fact, the qualifying effect that a film can have for a brand as a result of product placement is subject to the transience of memory. On the other hand, the brand survives longer than one's memory of the film and the characteristics associated to it in the film, and it draws on numerous tools to develop its own distinctive traits.

From a long-term perspective and from the viewpoint of promoting companies, every product placement can therefore be examined in depth, not only for the benefits it can produce in terms of communication, but for the transience of the effects developed and therefore for the need to activate additional tools that become necessary in order to achieve the company's communication objectives.

In this sense, product placement must be assessed in relation to the possibility of its being sustained, in the short term, by other communication initiatives that have positive repercussions on the film's popularity. Companies that have identified product placement as a tool of corporate communication with particular characteristics seem to be moving in this direction, i.e. towards the association of product placement with other corporate communication tools on one hand, and towards the choice of innovative forms of product presentation in the film and in the promotion of the films and of product placement itself on the other. 


\section{Bibliography}

Aaker David A., Myers John G., Advertising Management, Prentice-Hall, Englewood Cliffs, 1975.

Babin Laurie A., Carder Sheri Thompson, Viewers' Recognition of Brands Placed Within a Film, International Journal of Advertising, 15, pp. 140-151, 1996.

Baird Roger, Bond Secures L 35 M in Product Placement Deals, Marketing Week, 12 June1997.

Brennan Ian, Dubas Khalid M., Babin Laurie A., The Influence of Product Placement Type \& Exposure Time on Product-Placement Recognition, International Journal of Advertising, n. 18, 1999, pp. 323-337.

Brondoni Silvio M., Pubblicità collettiva, notorietà di prodotto e immagine di marca, Giuffré, Milano, 1987.

Brondoni Silvio M., Comunicazione, risorse invisibili e strategia competitiva d'impresa, Sinergie, 43-44, 1997, pp. 3-35.

Brondoni Silvio M. (ed.), Marketing Lexicon, CLUEB, Bologna, 1999.

Buss Dale, A Product Placement Hall of Fame, Business Week, 11 June 1998.

Colvin Geoffrey, Product Placement, Fortune, 16 December 1998.

de Mooij Marieke, Global Marketing and Advertising, Sage, Thousand Oaks, 1998.

Dignam Conor, Why Marketers Missed Out on Men in Black, Marketing, 14 August 1997.

Gupta Pola B., Lord K.R., Product Placement in Movies: the Effect of Prominence and Mode on Audience Recall, Journal of Current Issues and Research in Advertising, n. 20, 1998, pp. 47-59. http://dx.doi.org/10.1080/10641734.1998.10505076

Gupta Pola B., Stephen J. Gould, Consumers' Perceptions of the Ethics and Acceptability Product Placements in Movies: Product Category and Individual Differences, The Journal of Current Issues and Research in Advertising, n. 19, 1997, pp. 37-50.

http://dx.doi.org/10.1080/10641734.1997.10505056

Halliday Jean, Carmakers Open Their Doors to Films, Advertising Age, 14 April 1997.

Hurwood David L., How Companies Set Advertising Budgets, M. McNiven (ed.), How Much to Spend for Advertising? Methods for Determining Advertising Expenditure Levels, The Association of National Advertisers, New York, 1969.

Jensen Jeff, High hopes for 'Men in Black' and Ray-Bans, Advertising Age, 14 April 1997.

Karrh James A., Effects of Brand Placements in Motion Pictures, King K.W. (ed.), Proceedings of the 1994 Conference of the American Academy of Advertising, Athens, American Academy of Advertising, 1994, pp. 90-96.

Karrh James A., Brand Placement: a Review, Journal of Current Issues and Research in Advertising, 20, 1998, pp. 31-49.

http://dx.doi.org/10.1080/10641734.1998.10505081

Karrh James A., Frith Katherine Toland, Callison Coy, Audience Attitudes towards Brand (Product) Placement: Singapore and the United States, International Journal of Advertising, n. 20, 2001, pp. 3 24.

Lehmann Donald R., Weinberg Charles B., Sales Through Sequential Distribution Channels: An Application to Movies and Videos, Journal of Marketing, n. 64, July, 2000, pp. 18-33.

http://dx.doi.org/10.1509/jmkg.64.3.18.18026

Mandese Joe, Turner Placing New Spin on Deals, Advertising Age, 19 June 1995.

Mitchel Alan, The Power of a Plug, Management Today, February, 1996, pp. 81-82.

Nebenzahl Israel D., Secunda Eugene, Consumers' Attitudes Toward Product Placement in Movies, International Journal of Advertising, n. 12, 1993, pp. 1-11.

Nickel William G., Marketing Communications and Promotion, Grid, Columbus, 1976.

Nylen David W., Advertising: Planning Implementation and Control, South-Western Publishing Co., Cincinnati, 1975.

Quassim Ali, How Ericsson Uses James Bond to Build Brand Awareness, Campaign London, 16 January 1998. 
Ross Chuck, Johnson Bradley, Sky's the limit for Sony's ambitious Station plans, Advertising Age, 3 February 1995.

Russel Cristel A., Toward a Framework of Product Placement: Theoretical Propositions, Advances in Consumer Research, v. 25, 1998, pp. 357-362.

Spiggle Susan, 7-Up Art, Pepsi Art, and Sunklist Art: the Presentation of Brand Symbols in Art, Advances in Consumer Research, n. 12, 1985, pp. 11-16.

Turcotte Samuel, Gimme a Bud! The Feature Film Product Placement Industry, The University of Texas at Austin, USA, 1995.

\section{Internet sites}

advertising.utexas.edu www.1.50megs.com www.3.50megs.com www.dreamwater.com www.erma.org WWW.esmonitor.com Www.filmbiz.com www.fortune.com www.geocites.com/Hollywood/Pavillon/9263/index.html www.igc.org www.jmnanddy.com www.mgmua.com/bond/dossier.html www.multimania.com/spielbrg/ET/indexET.html www.topcities.com www.wired.com

${ }^{1}$ Cf. S.M. Brondoni, A lezione di trasparenza, Il Sole 24 Ore, $6{ }^{\text {th }}$ December 1999, p. 34.

${ }^{2}$ For a wide collection of examples in product placement of products, services and industrial goods, see www.jmnanddy.com.

${ }^{3}$ Product placement is often used in adult cartoon series like 'The Simpson', 'South Park', etc.

${ }^{4}$ New word from advertising and entertainment.

${ }^{5}$ In many artistic products the artist spontaneously introduces a product or a brand without a specific product placement contract. For an analysis of the motivations for the introduction of a product/brand in an artistic product, cf. S. Spiggle, 7-Up Art, Pepsi Art, and Sunklist Art: the Presentation of Brand Symbols in Art, Advances in Consumer Research, 1985.

${ }^{6}$ Cf. I. Brennan, K.M. Dubas, L.A. Babin, The Influence of Product-Placement Type \& Exposure Time on Product Placement Recognition, International Journal of Advertising, 1999, p. 323.

${ }^{7}$ Cf. Mission Impossible 2 (M-I:2, John Woo, USA, 2000) where Oakley sun glasses are used not as sun glasses but as a communication tool to transmit a secret message to Tom Cruise, the leading actor.

${ }^{8}$ Product placement can be distinguished in various types: screen placement, script placement, plot placement, as proposed in C.A. Russel, Toward a Framework of Product Placement: Theoretical Propositions, Advances in Consumer Research, 1998. Screen Placement can be seen just by eyesight, for example when a brand is placed on the background of a scene, on a road (creative placement), or when a brand is part of the decoration of a set (on-set placement), like for the products used to complete a kitchen set. Script placement is referred to the placement introduced in dialogues, which is perceived by ears. Plot placement is composed by a various combination of audio-visual elements. This distinction is particularly important because each of these placements grants a different type of recall (visual, auditive and a combination of both). 
${ }^{9}$ The leading actor drinks a beer of a particular brand in the topic scene of a movie; or, every time a beer is drunk, it is always the same brand.

${ }^{10}$ Ford cars, for example, can be used for every role (for 'the good guys' and for 'the bad guys') but they must not have problems with the engine, cf. S. Turcotte, Gimme a Bud! The Feature Film Product Placement Industry, The University of Texas at Austin, USA, 1995.

${ }^{11} \mathrm{We}$ are here referring to product placement in movies, which has been used many times during last century, granting a significant development of professionals and techniques and attracting many communication investments from corporations.

12 For an explication of 'active audience interest', cf. S.M. Brondoni, Pubblicità collettiva, notorietà di prodotto e immagine di marca, Giuffré, Milano, 1987, p. 40.

13 In many countries there are legislative limitations to advertisement for specific product categories as tobacco products, but movies showing actors (and well known stars) smoking and clearly exposing their cigarettes or cigars brand are legally diffused.

${ }^{14}$ Often, in compliance with the provisions of national laws, scenes showing products with legal communication restrictions can be cut out from movies. This process is easily feasible in movies realized with digital technologies. Sometimes, however, it is impossible to cut out a scene from a movie because the scene is a central one in the development of the story, or the costs of cutting out all the scenes with non allowed placements are too high to justify the process itself.

${ }^{15}$ Cf. A. Aaker, J.G. Mayers 1975, Advertising Management, Prentice-Hall, Englewood Cliffs; M. de Mooij 1998, Global Marketing and Advertising, Sage, Thousand Oaks; L. Guatri 1964, La pubblicità nell'economia dell'azienda industriale, Giuffré, Milano; J.J. Lambin 1976, Advertising, Competition and Oligopoly Over Time. An Econometric Investigation in Western European Countries, North Holland, Amsterdam; J.D. Little 1966, A Model of Adaptive Control of Promotional Spending, Operational Research, November-December, pp. 175-197; J.D. Little 1984, Decision Support Systems for Marketing Managers, American Marketing Association, New York.

${ }^{16}$ For companies using product placement it is very important to know the details of promotional plans of a movie, and be informed about all the contracts signed by the producer for the movie diffusion after the box office of the film circuit (i.e. home video), in order to know the kind and the wideness of the audience which can be exposed to the placement.

${ }^{17}$ Short promotional films, made up of the most significant scenes from the work, which are screened on television and in cinemas, to attract audiences.

${ }^{18}$ For a definition of licensing, cf. S.M. Brondoni (ed.), Marketing Lexicon, CLUEB, Bologna, 1999, p. 159.

19 'A placement along with a promotion is like icing on the cake. In the past, promotions have been done without it, but they're starting to realize that with it, it makes even more sense.' See S. Turcotte, Gimme a Bud!, cit., which quotes the words of Musette Buckley, Production Resources Manager at Warner Bros, October 1994.

${ }^{20}$ Films are usually promoted by trailers as well as by advertising and publicity.

${ }^{21}$ Cf. S. Turcotte, Gimme a Bud!, cit., which mentions, for example, how AT\&T had created 500 'placements' in 1993, while Ford had organised almost 350 all over the world.

22 The role of product placement agencies explains its specific geographical location: to develop their relations with the film production environment, agencies must be in close contact with the production houses and therefore be located in the Hollywood area, where most film production with consistent commercial prospects is located.

What is more, the importance of relations inside the product placement market is such that it justifies the presence of a specialist association to safeguard and spread understanding of this communication tool: ERMA (Entertainment Resources \& Marketing Association). It was founded in 1991 to give professional credibility to the product placement market and its operators, and to create precise communication to the media and the public referred to product placement. ERMA draws together film studios, promoting companies and product placement agencies (cf. www.erma.org).

${ }^{23}$ Agencies propose a wide range of services to promoting companies and to film studios. To start with, they offer their competence in the use of product placement, which covers the drafting of the contract and a capacity to manage placements during filming of the scenes. So they often act as 
warehouses for the products of promoting companies, reducing the logistical problems of product availability at film production houses. And finally, the main reason that explains the development of product placement agencies is the many and complex relationships that contacts with the environment has enabled them to develop.

${ }^{24}$ For example, we should consider the agency's utility when a scene has to be filmed in a supermarket. Thanks to its relations with the promoting companies, the agency can take charge of organising the shelves in the point of sale, so that the production house does not have to waste its resources' time dealing with various contacts that are often of little importance.

${ }^{25}$ For example, clothing products, food products or the services offered by service companies like airlines or hotel companies.

${ }^{26}$ For an analysis of the distribution of films by different and subsequent channels, cf. D.R. Lehmann, C.B. Weinberg, Sales Through Sequential Distribution Channels: An Application to Movies and Videos, Journal of Marketing, 2000.

${ }^{27}$ However we must remember that a product placement contract is not treated in the same way in all national legal systems. For an analysis of the interpretation of product placement in the Italian legal system, cf. G. Ghidini, L. Vasselli, Le sponsorizzazioni e la legge, Chamber of Commerce, Milan, 1999.

The considerations proposed in the text are linked to professional techniques, where product placement is formally applied by companies, stimulating researchers' interest. Cf. I. Brennan, K.M. Dubos, L.A. Babin, The Influence of Product-Placement Type \& Exposure Time on ProductPlacement Recognition, cit.

${ }^{28}$ Cf. S. Turcotte, Gimme a Bud!, cit. The transparency clause is compulsory, in particular for contracts that define remuneration for placements in television shows in the USA. On the other hand, it is not envisaged for film placements in the USA, although a great deal of information is often made available independently, cf. I. Brennan, K.M. Dubos, L.A. Babin, The Influence of Product-Placement Type \& Exposure Time on Product-Placement Recognition, cit.

29 The director must simultaneously consider the quality of the film in production and the lower contribution to production due to the absence of product placement which might cause specific scenes to be abandoned.

${ }^{30}$ Cf. Reebok v. Tristar, Dec. 1996, www.geocites.com/Hollywood/Pavillon/9263/index.html.

31 The contributions that production houses receive from product placement are lower than the value of the communication initiatives that companies can attract to support a film by cross promotion.

${ }^{32} \mathrm{Cf}$. S. Turcotte, Gimme a Bud!, cit. In particular, in view of the time necessary to generate cross promotion, promotion is often activated when the film reaches the home video circuit. Take the example of the promotion of the Casio G-Shock watch, seen in the film Speed (Jan De Bout, USA, 1995).

${ }^{33}$ Cf. S. Turcotte, Gimme a Bud!, cit.

${ }^{34}$ Investors in advertising, for example, make their own space/time purchasing decisions on the basis of the palimpsest of a TV network or from reading a daily paper or periodical, and the companies that sponsor an event must identity the specific values that the public associates with the event selected in advance.

${ }^{35}$ In a given scene, a product/brand can be presented in different ways: in the foreground, in the background, mentioned in the dialogue, used properly or improperly by the characters, etc. Each of the various 'ways' listed can clearly have different visibility, but also a different impact on the public's system of perception.

36 The company's 'functioning hypothesis' refers to its future as a going concern, and contrasts with the 'disposal hypothesis' that contemplates a break with the status of going concern. Cf. S.M. Brondoni, A. Di Gregorio, Brand Equity e politiche di comunicazione, Studio monografico, Progetto Comunicazione Aziendale, CREA-Bocconi University, no. 2/94, January 1995.

${ }^{37}$ Cf. S.M. Brondoni, Pubblicità collettiva, notorietà di prodotto e immagine di marca, cit.

38 E.T. - The Extra-Terrestrial (Steven Spielberg, USA, 1982) www.multimania.com/ spielberg/ET/indexET.html. The Hershey Food Corp. is a well-known U.S. company that produces 
chocolate but, at the time of E.T., it had only recently entered the snack market where it therefore enjoyed limited recognition. Cf. J.D. Reed, Plugging Away in Hollywood, Time, 2 January, 1989.

${ }^{39}$ It is important to note that the success that Hershey Food enjoyed in terms of awareness of Reese's Pieces came from a good combination of several corporate communication tools. The visibility of Reese's Pieces in Spielberg's film was very limited, in fact one would have had to know it already in order to recognise it in the film. Hershey Food's promotional activities therefore took the form of promotion and advertising programmed simultaneously with the screening of the film, reiterating its positioning in the film, developing it and extending its visibility. Cf. S. Turcotte, Gimme a Bud!, cit.

${ }^{40}$ Goldeneye, (Roger Spottiswoode, USA, 1995) www.mgmua.com/bond/dossier.html.

${ }^{41}$ Risk limitation identifies a distinctive characteristic of product placement, which differentiates it from the case of sponsorship. For example we must remember what happened to Canadian athlete Ben Johnson who tested positive for drugs during the 1988 Olympics in Seoul, causing huge damage to his image as an athlete, with serious repercussion for his sponsors' image.

${ }^{42}$ In this context we should mention the action taken by Kraft Foods, which makes Jell-O, when it demanded guarantees from the producers of the film Body Shots (originally Jello Shots, which narrates a night of debauchery under the influence of alcohol), that its product would not be called to account and associated with the film. This 'product displacement' was designed to avoid that the negative values associated with the film were transferred to Kraft's product (Cf. G. Colvin, Product Placement, Fortune, 16 December 1998).

${ }^{43}$ As Ford envisages when it always excludes by contract that its cars can have engine problems in a scene in a film.

${ }^{44}$ Cf. the case of Reebok v. Tristar.

${ }^{45}$ Tomorrow never dies, Roger Spottiswoode, USA, 1998.

46 The case mentioned recalls a particular situation, regarding a sector of supply that has existed for some time and tends not to be differentiated, in which the first efforts at differentiation were made recently, as we can also see for Evian and Avalon waters, which have used product placement extensively.

${ }^{47}$ The Firm (Sidney Pollack, USA, 1993). 